\title{
Fitness advice ignores realities of life on the margins
}

\author{
n Cite as: CMAJ 2020 January 27;192:E103-4. doi: 10.1503/cmaj.1095843
}

Posted on cmajnews.com on January 10, 2020

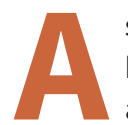

single mother texts the neighbour who watches her two kids after school - she'll be late picking them up because she missed the bus home from her second job. Waiting at the stop, she runs through her checklist of homework and chores to squeeze in before putting the kids to bed. Her doctor told her to find time for 20 minutes of exercise, but is that realistic?

Policy experts and physicians who serve low-income communities say physical activity guidelines lack relevance for the 3.5 million Canadians living in poverty. "Right now, I would say the guideline for those who are 18 to 64 doesn't reflect the reality of that single mom raising two kids on her own," says Cheryl Camillo, director of the Master of Health Administration program at the University of Regina and an associate of the North American Observatory on Health Systems and Policies.

Canada's physical activity guidelines recommend that adults spend at least 150 minutes per week doing activities that make them sweat a little and breathe harder. For example, the guidelines suggest going for a brisk walk around the block after dinner or taking a dance class after work.

Fewer than one in five Canadians follow that advice, and the poorest tend to report the lowest levels of activity. Studies have shown that poverty is a major barrier to physical activity; for example, being too poor to live in a safe, walkable neighborhood is a barrier to activity. Yet, the current guidelines seem to assume that everyone has the time and resources to achieve recommended activity levels, Camillo says.
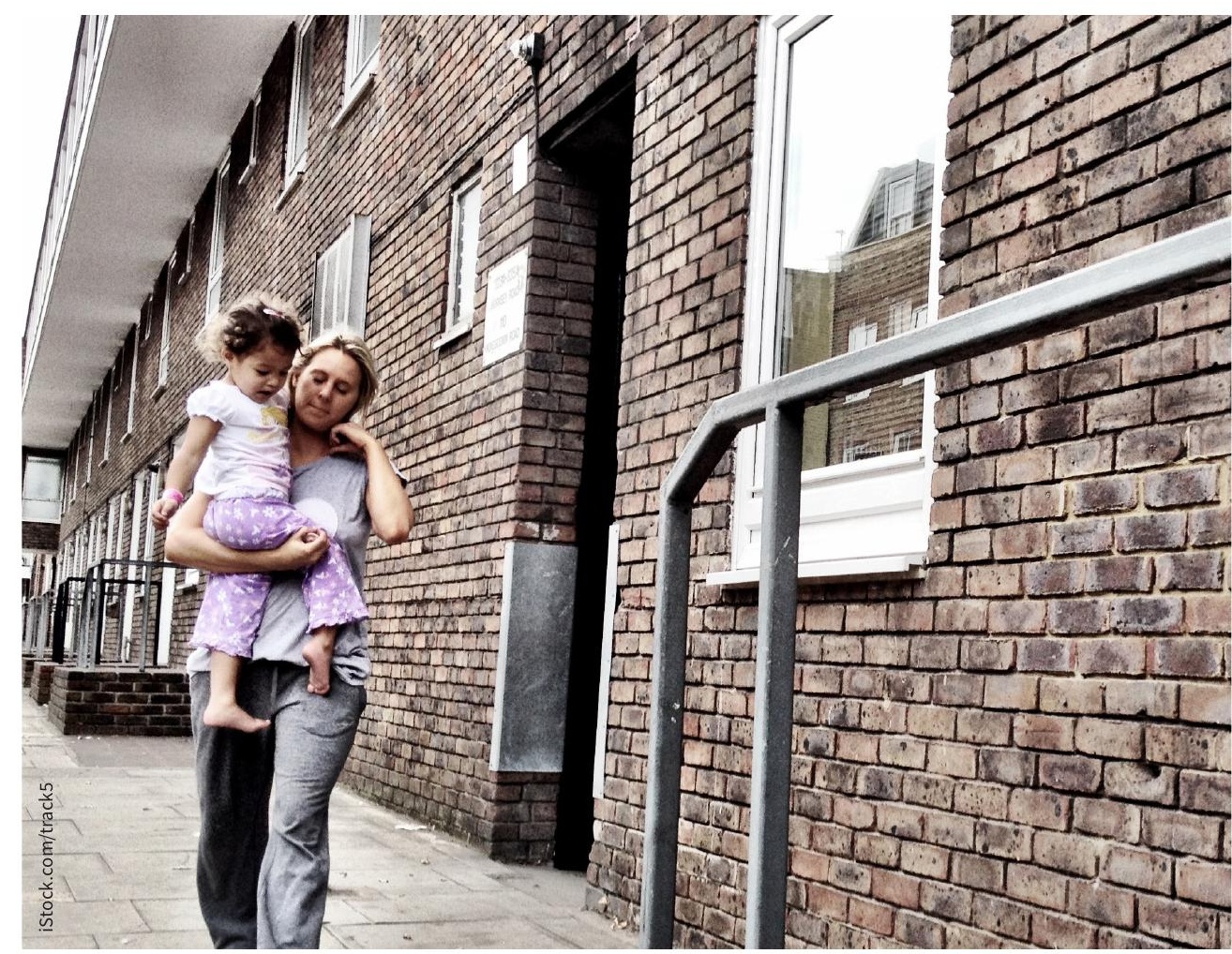

Most Canadians don't follow physical activity guidelines, but for those struggling to make ends meet, it's not only a matter of motivation.

Fitness experts closest to guideline development seem to embrace Nike's "Just Do It" philosophy. Robert Ross, who leads a panel developing the world's first 24-hour movement guidelines for adults, acknowledges that less affluent Canadians face more challenges in incorporating exercise into their routines than those in higher income brackets. However, he says, "that does not mean that people of lower socioeconomic status should say, 'Oh well, that's not for me. I can't do that.' Yes, they can." Ross, a professor of exercise physiology at Queen's University, says that time may be a more important barrier to exercise than income. "What that really says to me is that physical activity has not reached the priority that it needs to for them to allot some time to that in their 24-hour day."

According to Dr. Pierre Fremont, chair of the Sport and Exercise Medicine Committee for the College of Family Physicians of Canada, society could reap huge savings in health care spending avoided if even $1 \%$ more of the population got the recommended levels of exercise. Fremont says governments could use fiscal measures to make that easier for people in lower tax brackets, but also notes that 
regular exercise is accessible to most people and doesn't require expensive equipment.

However, physicians who work with patients living in poverty contend that prioritizing fitness is complicated by daily struggles for survival. Many of the children that pediatrician Dr. Mahli Brindamour sees at the Saskatoon Community Clinic are from low-income families. She recognizes that ensuring kids get enough physical activity may be one of her priorities as a doctor, but their families may have more pressing concerns. "In modern medicine, there are often things that we advise that are very difficult for people to follow," Brindamour says.

It's not only a matter of having enough money for extracurricular activities and equipment. She says people living in poverty often don't have the mental space to think about exercise when they're worried about keeping a roof over their heads or food on the table. Instead of putting the burden on vulnerable families to ensure kids get enough exercise, society should be integrating more activity into schools and other places children go regardless of their socioeconomic status, Brindamour says.

The environment in which people can afford to live may pose barriers that are difficult to overcome. One Quebec study found that schools in low-income areas had fewer facilities for physical activity and offered a lower diversity of intramural activities than those in high-income areas.
Another Canadian study found that kids in low-income neighborhoods also spend more time indoors. This may reflect them feeling unsafe outside; a Quebec study linked exposure to poverty with kids feeling less safe at school and, in turn, being overweight or obese.

Studies of adults suggest similar links between income, environment and activity. A Toronto study found people living in less walkable areas, particularly recent immigrants in low-income neighborhoods, had an accelerated risk of developing diabetes than those in more walkable, high-income areas. And in an older qualitative study published in 2000 , single women living in poverty in Edmonton cited social isolation and fears about going outside among their barriers to exercise.

Health policy experts say guidelines could provide more context-sensitive recommendations. According to Camillo, that might include suggesting that people who don't have a car walk part of their bus route, or those who commute for groceries because they live in a food desert strengthen their muscles by carrying home properly balanced shopping bags.

Dr. Tarun Katapally, a population health researcher and associate professor of public policy at the University of Regina, says the current guidelines may be relevant for everyone but he's not sure they're reasonable. "If you have to prioritize what's the most important thing for a family or an adult, I don't think it's putting physical activity on top and perhaps maybe they shouldn't," he explains.

Katapally says future advice should include voices from different communities. $\mathrm{He}$ also says the guidelines should go beyond how much exercise a person needs to addressing how, why and where different people prefer to be active.

In some cases, building community may be more important than building gyms. One study found that people in low-income communities were more likely to meet physical activity guidelines if they had larger social networks and a higher percentage of physically active people in those networks.

Over the past 40 years, Dr. James Irvine has watched rates of diabetes and heart disease climb in northern Saskatchewan's predominantly Indigenous population, over one-third of whom are in Canada's lowest income bracket. For Irvine, curbing that trend is less about encouraging patients to spend a set amount of time "doing exercise" and more about supporting them in reconnecting with activities that are culturally or geographically relevant. "Things like powwow dancing, or jigging, or canoeing, or land-based activities like snaring rabbits or trapping are all things that involve physical activity, but they also build on cultural strengths and identity," he says.

Greg Basky, Saskatoon, Sask. 